\title{
SELF-PERCEIVED AND UNMET GENERAL HEALTH NEED AMONG PLWHA IN NIGERIA
}

\author{
Adedigba $\mathrm{MA}^{1}$, Ogunbodede E, Jeboda $\mathrm{SO}^{2}$, and Naidoo $\mathrm{S}^{3}$
}

Abstract

Objective: This study set out to determine the self-reported unmet health needs of people living with HIV/AIDS (PLWHA) in a Nigerian population.

Methods: A prospective study conducted among consecutive 209 consenting PLWHA in the South-western Nigeria; who sought for care in the Obafemi Awolowo University Teaching Hospitals complex, Ile-Ife and General Hospital, Ilesa were recruited. Participants completed a comprehensive survey seeking information to determine their unmet needs in the following areas: Medication, Dental, Mental, Home care, Hospital admission, access to antiretroviral therapy and emergency services.

Results: One or more unmet needs were reported by $79.4 \%$ of the sample. Needs for medication, home-based care and mental care were more likely to be unmet. There was a statistically significant relationship between unmet needs and living arrangements $(\mathbf{p}<0.05)$.

Conclusions: Perceived oral health status was the factor that best predicted the unmet need. Perceived oral health status of these patients should be improved to reduce the level of the unmet needs.

Key words: Perceived, unmet needs HIV/AIDS.

\section{Introduction}

The needs of People living with HIV/AIDS (PLWHA) are numerous. They include counselling, medical, economical and complex psychosocial needs. Since the onset of the HIV pandemic, there have been various reports on oral manifestations of HIV/AIDS in sub-Saharan Africa and an increase in the seeking and obtaining dental care among PLWHA. This has led to promulgation and implementation of various treatment and care protocols $(1,2)$. Regular oral health care of PLWHA improves their quality of life. Early diagnosis and the provision of effective and efficient treatment are essential so that serious health consequences may be averted (3). In order to plan and allocate the often meagre resources, peculiar to the sub-Saharan Africa, it is important to determine what service needs are unmet.

There are a myriad of factors that influence the presence or absence of unmet dental needs. These factors include advanced level of illness $(4,5)$, lower income earners and holders of government owned or no medical insurance (6), lack of a usual source of care (7), living alone $(8,9)$, and areas with low AIDS prevalence $(10,11)$. Empirical work on the unmet oral health needs of HIV/AIDS patients in sub-Saharan Africa has not been done, but rather much effort has been directed towards documenting the prevalence of the oral manifestations of this disease.

In a study conducted in USA (12), half of the PLWHA perceived their oral health as fair or poor. Two out of every three reported that they had experienced pain in their mouth at least once in the previous year, and $75 \%$ reported a specific oral symptom. They reported that $60 \%$ of the respondents had lost some teeth; additional 9\% indicated that they were edentulous. Nearly half were in need of dental care the previous year, but could not obtain it. It has been reported that more than

Corresponding author: Adedigba M.A., Department of Preventive and Community Dentistry, Obafemi Awolowo University, Ile-Ife, 220005, Nigeria

Tel. +234-803714976, E-mail: adedigba@oauife.edu.ng or

ademich2002@yahoo.com

${ }^{1}$ Department of Preventive and Community Dentistry, Obafemi Awolowo University, Ile-Ife. ${ }^{2}$ Department of Preventive Dentistry, LUTH, Lagos. ${ }^{3}$ Department of Community Dentistry, University of Western Cape, Cape Town, RSA. half of PLWHA indicated the need for dental care in the previous three months before the survey (13). Mascarenhas and Smith (14), observed that PLWHA who perceived that their oral health as "excellent", had a significantly lower odds ratio of use (OR, $034,95 \% \mathrm{CI}$, $0.12-0.93)$ in that they tended to use the dental services much less once they felt their oral health was good.

Twenty two percent of PLWHA living alone were found to have an unmet need compared to $18 \%$ who lived with others (15). Those who live with others are likely to be positively influenced by such living arrangement. The people living together with a PLWHA can assist in care or direct such to where care can be obtained. This could be more so in an African setting where home-based care is common. Unmet oral health needs are likely to be great among PLWHA in African settings because care availability is often limited to dental school clinics and a few private practitioners. The community-based dental care of HIV-infected individuals will be a necessity in order to transport patients to and from the dental schools and hospitals.

The objective of this study was to determine the prevalence of the factors associated with self-perceived unmet general health service needs among PLWHA.

\section{Materials and Methods}

A prospective descriptive study was conducted among PLWHA in Ife-Ijesa zone of south-western Nigeria. Two hundred and nine consecutive patients out of 250 PLWHA participated in the study after providing written, informed consent. The inclusion criteria were possession of an Elisa-confirmed diagnosis of HIV/AIDS and consent to participate in the study. All respondents were attending HIV/AIDS clinics in General Hospital, Ilesa and Obafemi Awolowo University Teaching Hospitals Complex, Ile-Ife. Ethical clearance was sought and obtained from the Ethics and Research committee. Data were collected over a period of two years ( $1^{\text {st }}$ July 2002 to $31^{\text {st }}$ of July 2004) using a self-administered questionnaire adapted from Adedigba et al., (16), which was made up of five sections. Information were obtained on age, HIV status, gender, ethnicity, medical insurance status, level of education, marital status, employment, source of care in the last one year, cost of travelling, time 
of diagnosis, living arrangements, risk groups, and health status. Perceived oral health status (OHS) was based on self-report and was rated as Poor-1, Fair-2, Good- 3, Very good-4 and Excellent-5.

Information was sought to determine unmet needs in the following areas: Medication, Dental, Mental, Homebased care, Hospital admission, access to antiretroviral therapy and Emergency services. The unmet need was a composite score which is a discrete continuous variable. The clinical stage of the disease was determined by using the staging proposed WHO EC-Clearinghouse (17). The data was processed using IBM compatible microcomputer with the aid of EPI-INFO software (version 2000) (18) and Intercooled Stata 9.2 for windows (19). Relationships between categorical independent variables and unmet need were analysed by the chi-square test for association. A general linear regression model (Poisson) was used to assess the predictors of unmet need which was a discrete continuous variable. The regression model was checked for consistency using standard techniques and tests of heterogeneity and trend were carried out and all were within satisfactory limits. Indicator variables were created for different categories of oral health status and comparison done using the poorest oral health status as the reference.

\section{Results}

There were 76 (36.4\%) male and 133 (63.9\%) female among the respondents. The age groups 21-30 (74, $35.4 \%)$ and $31-40(73,34.9 \%)$ represented most of the patients seen. The median age was 34.0 yrs (mean 35.5, $\mathrm{SD} \pm 10.0$ ). Half of the respondents were unemployment since they were diagnosed HIV sero-positive. All participants were already in one stage or the other of AIDS based on WHO classification (17) as shown by Table 3. There were more married females subjects (73, $34.9 \%$ ) compared to the males $(46,22.0 \%)$ and more widows $(20,9.6 \%)$ than widowers $(4,5.3 \%)$. Ninety-six $(45.9 \%)$ females were living with their family, while 24 $(11.5 \%)$ males were living alone (Table 1$)$.

There was only one male who had a medical insurance. There were 134 (64.4\%) and 74 (35.6\%) who earned below and above the poverty line respectively. The poverty line was put at US\$260:00 (38,480:00 Naira) per annum as at year 2003 (20).

The self-reported OHS were as follows: Poor-72 (34.4\%), Fair-55 (26.3\%), Good-28 (13.4\%), Very good35 (16.7\%), Excellent-19 (9.1\%). Nearly eighty per cent reported one form of unmet health needs. The highest perceived unmet health need was medication $(48.3 \%$ patients) while reported dental care need was $0.5 \%$. Seventy seven per cent sought for care from the medical centres.
Table 1: Socio-demographic data according to gender

\begin{tabular}{|c|c|c|c|c|c|c|}
\hline & \multicolumn{3}{|c|}{$\begin{array}{l}\text { Gender } \\
\text { Male }\end{array}$} & \multicolumn{3}{|c|}{$\begin{array}{l}\text { Total } \\
\text { Female }\end{array}$} \\
\hline & No & $\%$ & No & $\%$ & No & $\%$ \\
\hline \multicolumn{7}{|l|}{ Marital status } \\
\hline Married & 46 & 22.0 & 73 & 34.9 & 119 & 56.9 \\
\hline Single & 20 & 9.6 & 28 & 13.4 & 48 & 23.0 \\
\hline Widow (er) & 4 & 1.9 & 20 & 9.6 & 24 & 11.5 \\
\hline Divorced & 6 & 2.9 & 12 & 5.7 & 18 & 8.6 \\
\hline Total & 76 & 36.4 & 133 & 63.6 & 209 & 100.0 \\
\hline \multicolumn{7}{|c|}{ Living Arrangements } \\
\hline Living alone & 24 & 11.5 & 37 & 17.7 & 61 & 29.2 \\
\hline Living with family & 52 & 24.9 & 96 & 45.9 & 148 & 70.8 \\
\hline Total & 76 & 36.4 & 133 & 63.6 & 209 & 100.0 \\
\hline
\end{tabular}

Table 2: Health needs Unmet Health needs parameterHave general health needs?

\begin{tabular}{lcl}
\hline & No & \% \\
\hline & & \\
NO & 43 & 20.6 \\
YES & 166 & 79.4 \\
Total & 209 & 100.0
\end{tabular}

Type of general health needs

$\begin{array}{lll}\text { No need } & 43 & 20.6 \\ \text { Medication } & 101 & 48.3 \\ \text { Mental } & 12 & 5.7 \\ \text { Home care } & 37 & 17.7 \\ \text { Dental } & 1 & 0.5 \\ \text { Admission/Hosp.care } & 2 & 1.0 \\ \text { Emergency } & 13 & 6.2 \\ \text { Total } & \mathbf{2 0 9} & \mathbf{1 0 0 . 0}\end{array}$

\begin{tabular}{lcl} 
Access to HAART & & \\
NO & 189 & 90.4 \\
YES & 20 & 9.6 \\
Total & $\mathbf{2 0 9}$ & $\mathbf{1 0 0 . 0}$ \\
& & \\
Sources of care in the last one year & \\
Religious & 5 & 2.4 \\
Alternative & 1 & 0.5 \\
Traditional & 9 & 4.3 \\
Private & 33 & 15.8 \\
Government & 161 & 77.0 \\
Total & 209 & 100.0 \\
\hline
\end{tabular}

There was a statistically significant difference between living arrangements and general health needs: those living with others were more likely to have more unmet health needs compared with those who live alone $\left(\chi^{2}=13.34, \mathrm{df}=1, \mathrm{p}=0.001\right)$. The unmet health needs were grouped into two for the purpose of analysis - the less and more intensive needs. The less intensive needs were medication, mental health care, home-based care and dental needs and more intensive needs were hospital care/admission and emergency needs. Living arrangements did not determine the level of intensive unmet health needs of the PLWHA ( $p>0.05)$.

The result of the test of differences between the annual income and unmet health needs of PLWHA was statistically significant (range 0.0-135853.50, $\mathrm{t}=7.38$, 
$\mathrm{p}<0.001)$-the higher the income the higher the likelihood of low unmet health needs. From the table 4, age, female gender, ethnicity, level of education, income per annum, living arrangements, medical insurance, time of diagnosis, risk groups, sources of care in the last one year, distance to clinic and cost of travelling did not influence unmet needs. The oral health status was a significant predictor of unmet needs. Using the worst oral health status designated as poor oral health as reference, the unmet need score was 0.093 greater in those with fair oral health $(95 \% \mathrm{CI},-0.09,0.27), \mathrm{p}$ value $=0.32$. When good oral health status was compared with that of poor oral health status, the unmet need sore was -0.26 greater in those with good oral health status $(95 \% \mathrm{CI}, 0.52,0.00)$, $\mathrm{p}$ value $=0.05$. This is also true for the very good and excellent oral health status with the level of significance highest for the excellent oral health status $(95 \% \mathrm{CI},-1.21$, 0.43 and $\mathrm{p}<0.001)$ and unmet need lowest $(-0.0 .8)$. However, the test of heterogeneity was significant, $\left(\chi^{2}=\right.$ $33.48, \mathrm{p}<0.001)$ showing the unmet needs varied with the different states of oral health. There was also trend of increasing unmet needs as the oral health got worse, (or vice versa). A test of trend was significant, $\chi^{2}=25.72, p<$ 0.001 (Figure 1).

There was no statistically significant difference in the unmet health needs between those that received their care from the medical and non-medical sources $\left(\chi^{2}=0.54\right.$, df $=2, \mathrm{p}=0.538$ (Fisher's exact)). From Table 5, the examined socio-demographic factor had no statistically significant relationship with the unmet health needs $(\mathrm{p}>0.05)$.

Table 3: General health needs and stage of the disease

\begin{tabular}{lllllllllll}
\hline \multicolumn{1}{l}{ General health needs } & \multicolumn{1}{c}{ Stage of the disease } \\
& I & II & \multicolumn{1}{c}{ III } & \multicolumn{3}{l}{ IV } & \multicolumn{2}{l}{ Total } \\
& No & $\%$ & No & $\%$ & No & $\%$ & No & $\%$ & No & $\%$ \\
\hline No & 11 & 50.0 & 13 & 28.9 & 18 & 15.0 & 3 & 13.6 & 45 & 21 \\
Yes & 11 & 50.0 & 32 & 71.1 & 102 & 85.0 & 19 & 86.4 & 164 & 78.5 \\
Total & 22 & 100.0 & 45 & 100.0 & 120 & 100.0 & 22 & 100.0 & 209 & 100.0 \\
\hline
\end{tabular}

$\chi^{2}=15.84, \mathrm{df}=3 \mathrm{p}=0.001$

Table 4: Summary of multivariate regression analysis on relationship between unmet health needs and predictor variables

\begin{tabular}{lrrrrr}
\hline Unmet need & Coefficient & \multicolumn{1}{l}{ Std error } & \multicolumn{1}{l}{ Z } & \multicolumn{1}{c}{$\mathbf{9 5 \%}$ CI } \\
\hline Age (years) & -0.0018793 & 0.0040636 & -0.46 & 0.644 & $-0.0098438 ; 0.0060851$ \\
Female gender & -0.0657538 & 0.0868564 & -0.76 & 0.449 & $-0.2359892 ; 0.1044817$ \\
Ethnic group & -0.0489077 & 0.055035 & -0.89 & 0.374 & $-0.1567744 ; 0.580589$ \\
Level of education & 0.0154081 & 0.0501773 & 0.31 & 0.759 & $-0.0829377 ; 0.1137538$ \\
Income per annum (Naira) & $-9.73 \mathrm{e}-080$ & $3.11 \mathrm{e}-07$ & -0.31 & 0.754 & $-7.06 \mathrm{e}-07 ; 5.12 \mathrm{e}-07$ \\
Living with family & 0.0739453 & 0.0905007 & 0.82 & 0.414 & $-0.1034328 ; 0.2513234$ \\
Medical insurance & 0.6706249 & 0.4699461 & 1.43 & 0.154 & $-0.2504525 ; 1.591702$ \\
Time of diagnosis (months) & 0.0015387 & 0.0036197 & 0.43 & 0.671 & $-0.0055558 ; 0.0086332$ \\
Risk groups & 0.0880355 & 0.483684 & 1.82 & 0.069 & $-0.0067647 ; 0.1828358$ \\
Fair oral health & 0.0925305 & 0.0930859 & 0.99 & 0.320 & $-0.0899145 ; 0.2749756$ \\
Good oral health & -0.2601488 & 0.1347593 & -1.93 & 0.054 & $-0.5242722 ; 0.0039746$ \\
Very good oral health & -0.3693464 & 0.124835 & -2.96 & 0.003 & $-0.6140184 ;-0.1246743$ \\
Excellent oral health & -0.08210487 & 0.197484 & -4.16 & 0.000 & $-1.20811 ;-0.4339871$ \\
Sources of care in last one year & -0.0242781 & 0.0491222 & -0.49 & 0.621 & $-0.1205558 ; 0.0719996$ \\
Dist6ance from clinic (kilometres) & 0.0004638 & 0.0006318 & 0.73 & 0.463 & $-0.0007745 ; 0.0017021$ \\
Cost of travelling (Naira) & -0.0001606 & 0.0002258 & -0.71 & 0.477 & $-0.0006032 ; 0.0002821$ \\
Constant & 1.431811 & 0.3972257 & 3.60 & 0.000 & $0.6532631 ; 0.210359$ \\
\hline
\end{tabular}


Table 5: The relationship between socio-demographic factors and unmet needs.

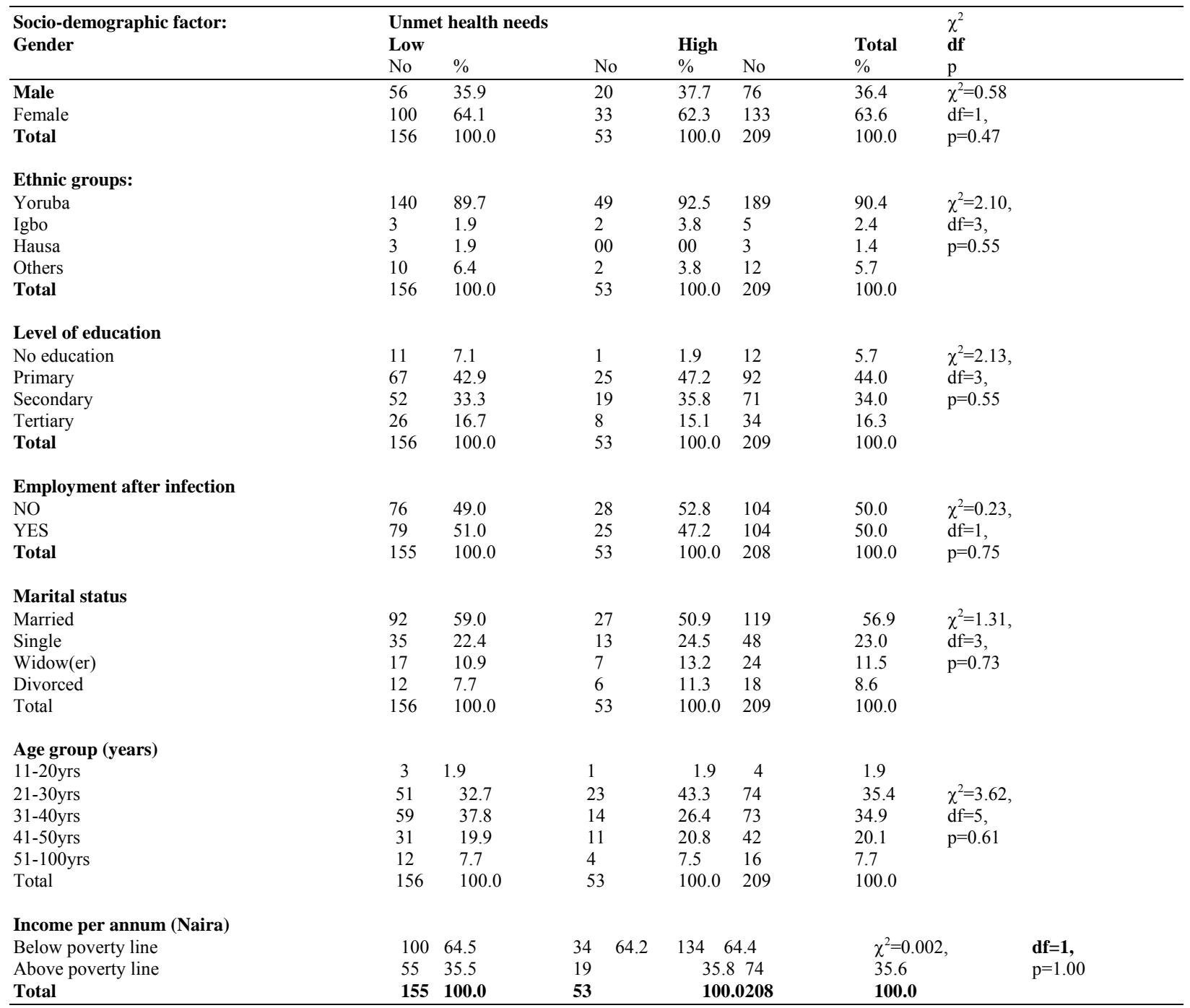

Figure 1: Showing the trend relationship between Unmet health needs and perceived Oral health status.

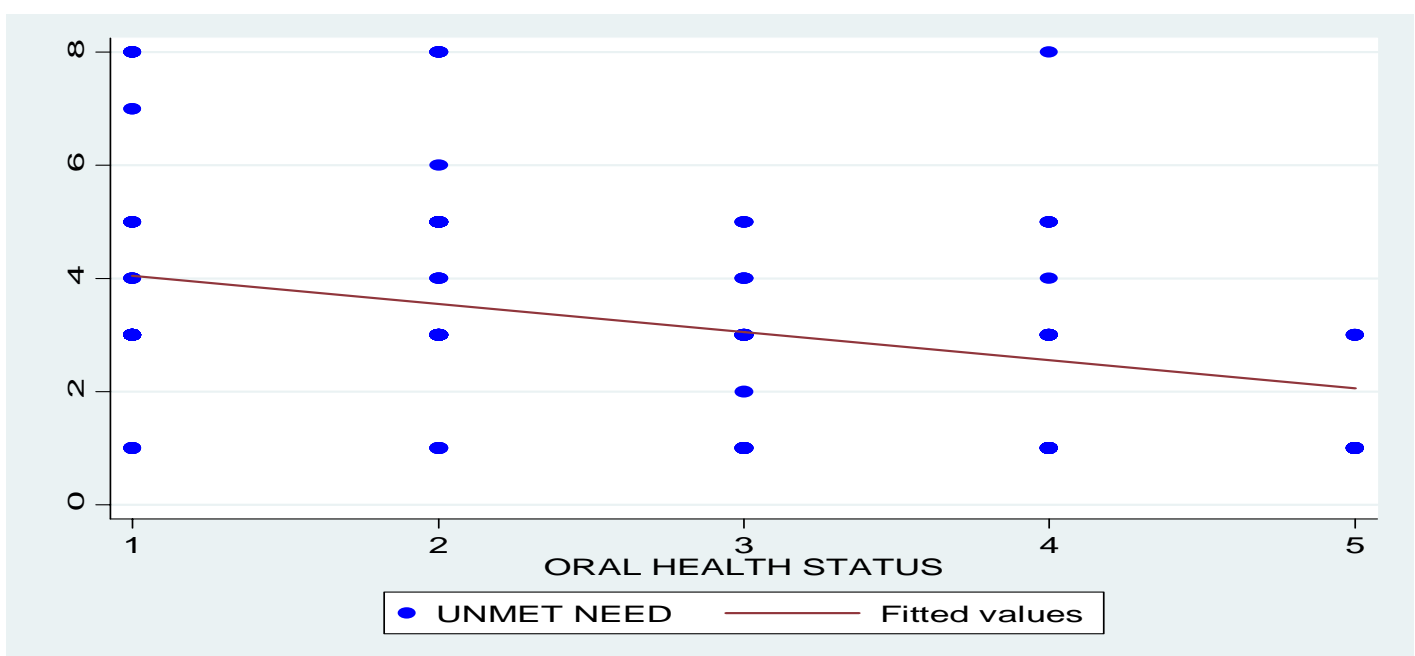




\section{Discussion}

There were more female PLWHA than the males. This may be due to the fact that more female are involved in this disease (21). Half (51.1\%) of the female had no formal education. The majority earned below the poverty level. This was not unexpected as the level of unemployment among PLWHA examined was very high because the majority lost their job due to the disease which invariably leads to enhanced poverty.

The use of Home-based care was seriously lacking in this study. This would have probably reduced the need for PLWHA to attend hospitals for care and treatment of HIV lesions. Home-based care reduces the workload of the health care providers and lowers the economic burden of rural/local health care centres to care for HIV/AIDS patients (22). Furthermore, rural clinics or primary health care centres may not require the highly trained staff required in teaching hospitals. Members of the community could be trained to work in the rural clinics and home-based care centres under the supervision of trained nurses. It has been previously reported that such an arrangement reduces both the in- and out-patient cost of the treatment of HIV/AIDS patients and the trend of the terminal stage of the disease becoming more expensive, can be reversed with the use of home-based care (23).

Nearly eighty per cent reported unmet general health needs. Several factors had been hypothesized to be responsible including advanced stage of illness $(4,5)$. In the present study there was a statistically significant relationship between stage of the disease and unmet general health needs $\left(\chi^{2}=15.84, \mathrm{df}=3, \mathrm{p}=0.001\right)$ (Table 3$)$. The more advanced the disease the more the symptoms and general health needs to meet them. This increase might account for the increase level of unmet health needs as in agreement with other studies $(15,24,12)$. Dental services have been the most commonly reported unmet need, followed by mental health services, and medications (15). This was not in agreement with the present study where dental health needs was the least. The possible reasons for this may be due to poor oral health awareness of the PLWHAs and that of the general population in Nigeria, poor access to modern dental treatment and high ratio of dentists to the general population who are majority located in the urban centres (25). None the less, Oral health care workers should be competent to care and manage oral HIV lesions especially as the disease proceeds to advance stage $(13,16)$.

Dutton (6) proposed higher unmet health needs with those earning lower income, public or with no insurance. The majority of the participants in the present study earned below the poverty line per annum (20) and had no medical insurance. These factors may result in the lack of enabling factors for meeting their health needs as the period of diagnosis of HIV/AIDS increases $(13,15,24)$.

The lack of usual source of care such as the government and private hospitals has been reported to influence unmet health needs (7). This is contrary to the finding of the present study, where over $90 \%$ utilised the private and government hospitals for care, still reported very high unmet needs. Although there was no statistical significant difference between unmet health needs and source of care $\left(\chi^{2}=0.54, \mathrm{df}=2, \mathrm{p}=0.54\right)$. This finding may be due to the fact that health care workers offered little or no care/treatment for the PLWHA. It has been documented that Nigerian oral health care workers prefer that HIV/AIDS patients be treated in designated centres (26). Fear of stigmatisation and lack of money may be other reasons.

There was statistically significant association between unmet health needs and living arrangements $\left(\chi^{2}\right.$ $=13.34, \mathrm{df}=1, \mathrm{p}=0.001$, (Fishers exact). This finding was contrary to previous reports $(8,11)$. This difference may be due to the low levels of oral and health awareness of the family members, poverty and fear of association with an HIV/AIDS infected family member, which may lead to stigmatisation of the whole family. There was no significant relationship between the dependent and the individual predictor variables at 0.05 level except for the perceived oral health status $(\mathrm{p}=0.000)$ (Table 4$)$. This means that the other predictor variables do not statistically predict the unmet health needs among the PLWHA but perceived oral health status do. Even though a significant relationship exists between the unmet health needs and the predictor variables, it was only perceived oral health status that could be relied upon to predict the unmet health needs. When poor oral health status was taken as a reference point, the level of significance increases for fair, good, very good and excellent $(0.32$, $0.54,0.003$ and 0.000 respectively). As the level of significance increases so is the level of Unmet needs decreases among the PLWHAs (Fig.1). The successful treatment of oral HIV lesions will encourage the intake of food, drinks and other nutritive materials which in turn prevents avoidable weight loss, dehydration and poor general health, which are very commonly seen among HIV/AIDS patients. Also, the recognition and prompt diagnosis of oral HIV lesions is often made first by the dental surgeon. This warrants the care and treatment from the dental heath care workers. In few of the possible association between unmet general needs and poor oral health status, which one leads to the other, will need to be determined by future research.

The relationship between socio-demographic characteristics and unmet health needs was not found to be significant $(p>0.05)$. This was in agreement with Fleishman et al (24). The lower level of unmet needs observed among $79(\mathrm{n}=104,51.0 \%)$ who were employed could be that they could afford care (see Table 5). This agreed with Capilouto et al (13), that the higher-income earners were not likely to report a dental need. The result obtained in this study was likely to be due to the low income status of the subjects, which might not have afforded them the expressed need for their oral conditions.

\section{Limitations:}

There were some short comings associated with self reporting studies in that its accuracy may be questioned. The cross-sectional un-control design of this study may limit its findings to that of the study population and careful inferences to the general population may be required. Also the patients were recruited consecutively 
and not randomised may not allow direct interpretation to the general population.

\section{Conclusions}

The level of unmet health needs was high in this study. The level of unmet health needs could be predicted by the perceived oral health status of the PLWHAs. If the perceived oral health status was poor, the level of unmet health needs increased. There was no statistical significant difference in level of unmet health needs between those PLWHA living alone and with family. There is a need for family members to care, assist and encourage PLWHA to seek care. Oral health policy makers need to bridge the gap of unmet oral health needs of PLWHA in the sub-Saharan African countries.

\section{References:}

1. Arendorf T, Sauer G, Bredekamp B \& Cloete AC. Guidelines for the Diagnosis and Management of Oral Manifestations of HIV Infection and Diagnosis and Management of Oral Manifestations of HIV Infection and
AIDS. Department of Oral Medicine and Periodontology, Faculty of Dentistry, University of the Western Cape/WHO Collaborating centre for Oral Health, 1995; ISBN 1-86808-306-3.

2. Scully C, Laskaris C, Pindborg J, Porter SR \& Reichart P. Oral manifestations of HIV infection and their management 1. More common lesions. Oral Surg Oral Med Oral Pathol 1991; 71: 158-66.

3. EEC Clearinghouse on Oral Problems Related to HIV Infection and WHO Collaborating Centre on Oral Manifestations of the Human Immunodeficiency Virus. An update of the classification and diagnostic criteria of oral of oral lesions in HIV infection. J Oral Path and Med 1991; 20:97 4. Piette J.D, Mor V, Mayer K, Zierler S. \& Wachtel T. The effects of immune
status and race on health service use among people with HIV disease. Am J Public Health 1993; 83: 510-514.

5. Solomon L, Frank R, Valhi D \& Astemborski J. Utilisation of health services in a cohort of intravenous drug users with known HIV-1 serostatus. Am J in a cohort of intravenous drug

6. Dutton D. Financial, organisational and professional factors affecting health care utilization. Soc Sci \& Med 1986; 23: 721-735.

7. Cornelius L., Beauregard K. \& Cohen J. National medical expenditure survey: Usual sources of care and their characteristics. Research findings 11. Agency for Health Care Policy and Research Rockville Maryland; 1991.
8. Greenley J.R. Sociocultural and psychological aspects of utilisation of health services. In Brenner HM, Mooney A and Nagy TJ (Eds.). Assessing the contributions of social sciences to Health. Boulder, Colorado: Westview Press; 1980.

9. Berkman L.F. Assessing the physical effects of social networks and social support. In Annual Review of Public Health, edited by Breslow L, Fielding JE and Lave LB. Palo Alto, California; Ann Rev 1984; 413-432.

10. Smith J.E., Landau C.S.J. \& Bahr G. AIDS in rural and small town America. AIDS Patient Care 1990; 17-21.

11. Navarro $M$. Where AIDS is a stranger: 11 years into the epidemics few outside urban areas find support or help. New York Times 1992; 25: B-1.

12. Shiboski C.H, Palacio H, Neuhaus J.M, \& Greenblatt R.M. Dental care

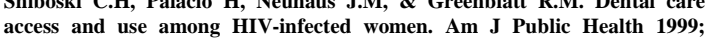
89(6):834-839.

13. Capilouto E.I., Piette J., White B.A, \& Fleishman J. Perceived need for dental care among persons living with acquired immunodeficiency syndrome. Med Care1991; 29: 745-754.

14. Mascarenhas A.K. \& Smith S.R. (1999) Factors associated with utilisation of care for oral lesions in HIV disease. Oral Surg Oral Med Oral Pathol 87 ; (6): care for or

15. Bonuck K.A, Arno P.S, Green J. et al. Self-perceived unmet health care needs of persons enrolled in HIV care. J Comm Health 1996; 21(3): 183-198

16. Adedigba M.A., Ogunbodede, E.O., Jeboda, S.O., Naidoo, S. Oral health treatment needs of HIV/AIDS patients in Ife-Ijesa zone, Nigeria. Tanz Dent $J$ 2007; 14 (1): 8-14

17. WHO/EC-Clearinghouse on oral problems related to HIV-infection and WHO collaborating centre on oral manifestations of the Immunodeficiency virus. Classification and diagnostic criteria for oral lesions in HIV-infection. vournal of Oral Pathol and Med 1993; 19: 232-234.

18. Dean A.G. \& Dean J.A. EPI Info. Version 2000: A word processing, database and statistics program for public health on IBM-compatible microcomputer Centres for Disease Control and Prevention, Atlanta: USA.

19. Stata- Intercooled stata 9.2 for Windows. Copyright $\odot$ 1985-2006

20. World Bank publication (2004). http://www.worldbank.org/ accessed: 12/04/2005.

21. Gilks CF. The challenge of HIV/AIDS in Sub-Saharan Africa. J RColl Physicians

40. 1999; 33:180-184

22. Bateman C. Can KwaZulu-Natal hospitals cope with the HIV/AIDS human tide? SAMJ 2001; 91(5): 364-368.

23. Halie B. (2000) Affordability of Home-Based Care for HIV/AIDS. SAMJ 90; (7): 690-691.

24. Fleishman J.A, Schneider D.A, Garcia I, \& Hardwick K. Dental service use among adults with human immunodeficiency virus infection. Med Care 1997; 35: 77-85.

25. Akpata, E.S. “Oral health in Nigeria”. Int Dent J 2004; 54 (6 Suppl 1): 361 366,

26. Adedigba MA, Ogunbodede EO, Fajewonyomi B A, Ojo O.O, \& Naidoo S. Gender differences among oral health care workers in caring for HIV/AIDS patients in Osun state, Nigeria. Afr Health Sci. 2005; 5 (3):182-187. 